\title{
Renal allotransplantation in retroperitoneal fibrosis: technical aspects
}

\author{
J Arudchelvam¹, M Z M Zafras'1, B Jeffrey Rajiev', L Nazar ${ }^{1}$
}

Ceylon Medical Journal 2018; 63: 86-87

DOI: http://doi.org/10.4038/cmj.v63i2.8688

\section{Introduction}

Retroperitoneal fibrosis is a rare disorder characterized by chronic inflammation and marked fibrosis of retroperitoneal tissue. End stage renal failure due to ureteric obstruction by retroperitoneal fibrosis requires kidney transplantation. But this may be impossible due to vascular entrapment. We describe a technique to approach the external iliac vessel from the femoral vessel proximally for kidney transplantation.

\section{Case report}

58-year-old female was diagnosed with end stage renal failure due to hydronephrosis and recurrent urinary tract infections as a result of ureteric narrowing due to retroperitoneal fibrosis. She was prepared for live donor kidney transplantation.

A curved suprainguinal incision was made on the left side. The peritoneum was firmly adherent to retroperitoneal area therefore access to the iliac vessels was impossible. Therefore the femoral vessels were mobilized at the inguinal ligament and iliac vessels were mobilized proceeding proximally by dividing the thickened peritoneum. Renal vessels were anastomosed to external iliac vessels. Extravesical ureteroneocystostomy was done over a stent. The patient had immediate urine output. Patient had an uneventful post-surgical period.

\section{Discussion}

Retroperitoneal fibrosis is a rare disorder with an incidence of $1.3 / 100,000$ [1]. It is characterized by chronic inflammation and marked fibrosis of retroperitonel tissues, which entraps the ureters and vessels [2]. There

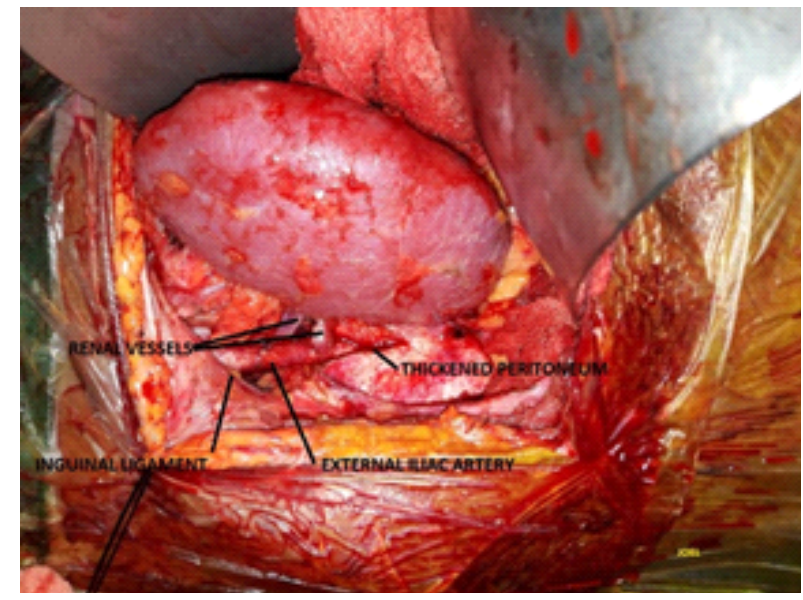

Figure 1. Post renal transplantation.

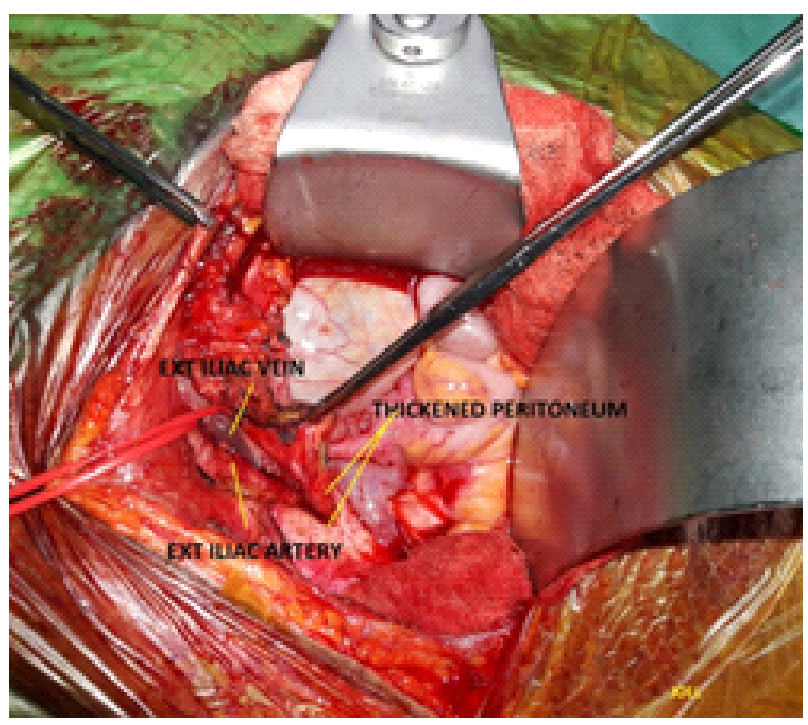

Figure 2. External iliac vessels after dissection showing thickened retroperitoneal tissues.

${ }^{1}$ National Hospital, Sri Lanka.

Correspondence: JA, e-mail: <joelaru@yahoo.com>. Received 15 May 2018 and revised version accepted 21 May 2018.

This is an open-access article distributed under the terms of the Creative Commons Attribution License, which permits unrestricted use, distribution, and reproduction in any medium, provided the original author and source are credited. 
are idiopathic (as in our patient) and secondary forms. Renal failure due ureteric obstruction is common [3]. Only very few reports of kidney transplantation in such patients.

Our intra operative strategy was to trace the vessels from femoral vessels proximally. Dissection was easier as it was from relatively normal tissue to the fibrotic tissue and long length ureter was not needed by anastomosing the renal vessels to lower external iliac vessels, and the graft was kept in a relatively stable position in the left iliac fossa.

\section{References}

1. van Bommel EFH, Jansen I, Hendriksz TR, Aarnoudse ALHJ. Idiopathic retroperitoneal fibrosis: prospective evaluation of incidence and clinicoradiologic presentation. Medicine (Baltimore) 2009; 88(4): 193-201.

2. Gilkeson GS, Allen NB. Retroperitoneal fibrosis. A true connective tissue disease. Rheum Dis Clin North Am 1996; 22: $23-38$

3. Corradi D, Maestri R, Palmisano A, et al. Idiopathic retroperitoneal fibrosis: Clinicopathologic features and differential diagnosis. Kidney Int 2007; 72: 742-53. 